\title{
An Overview of the Circular Economy among SMEs in the Basque Country: A Multiple Case Study
}

\author{
Marta Ormazabal (ID, Vanessa Prieto-Sandoval (D), Carmen Jaca (D), Javier Santos (D) \\ Industrial Management Department. Tecnun-School of Engineering. University of Navarra (Spain) \\ mormazabal@,tecnun.es, vprieto@,tecnun.es, cjaca@,tecnun.es,jsantos@,tecnun.es
}

Received: July 2016

Accepted: October 2016

\section{Abstract:}

Purpose: This research analyzes the maturity of environmental management as well as the degree of to which the Circular Economy has been implemented in Basque SMEs.

Design/methodology/approach: A total of 17 case studies were carried out in industrial SMEs companies in the Basque Country.

Findings: The main results show that companies are limited to complying with the law and in many cases are worried about the image of the company, although they are not committed to environmental issues. There is still a lot to do in SMEs, as they are the companies that face the biggest challenges due to a lack of resources.

Originality/value: Circular Economy aims to change a linear economy into promoting sustainability of the economy while also engaging in sustainable environmental protection. This research has focused on small and medium enterprises as they represent a 99\% of companies in Europe and they are the ones that have the most difficulty reaching a stage of environmental excellence due to their limited resources.

Keywords: circular economy, basque industry, industrial ecology 


\section{Introduction}

It is widely known that environmental management has emerged as an issue of great interest among companies (Céspedes-Lorente \& De Burgos-Jiménez, 2004), and in recent years the dissemination of environmental management tools and standards has spread widely among companies (Boiral \& Gendron, 2011). In addition, a change from a traditional linear economy which consists of "take, make, use and waste" is needed. This change involves closing the loop of materials, energy and waste flows, which is what the Circular Economy (CE) proposes (Geng \& Doberstein, 2008).

Nevertheless, not all companies have reached the same maturity stage in environmental terms, and some of them have never heard about CE. Moreover, SMEs are the ones that have the greatest difficulty reaching a stage of environmental excellence due to their limited resources (Shi, Peng Liu \& Zhong, 2008). In the Organization for Economic Cooperation and Development (OECD) countries, 95\% of companies are small and medium enterprises (SMEs) and generate two-thirds of employment. Specifically in the European Union, SMEs represent 99\% of all enterprises (Filipe, Grammatikos, \& Michala, 2016). Given this, this research intends to analyze the willingness of SMEs to implement circular economy through the study of Basque cases according to their environmental management maturity level and to identify the opportunities and challenges that $\mathrm{CE}$ would entail.

\section{Literature Review}

According to the purpose of this research, the literature review is focused in the exploration of the circular economy concept, the levels of integration and the environmental management maturity levels which may influence the circular economy implementation in the supply side of the market.

\subsection{Circular Economy}

The Circular Economy is not a new philosophy, but the term first appeared in the literature in the early nineties in a paper by Pearce and Turner (1990). Nevertheless, the concept was implemented into law in 1996 when Germany introduced the "Kreislaufwirtschaft" law to encourage the implementation of CE (Bilitewski, 2007; EEA, 2011). It proposes a restorative and regenerative economic model as a solution to the need for environmental resilience that is coherent with an economic tendency toward growth (Ellen MacArthur Foundation, 2012; Park, Sarkis \& Wu, 2010), which means a cycle of take/make, use and return/enrich. In the $\mathrm{CE}$ conception, take/make refers to the way industries take resources from the environment to transform them into goods and services. The product/service is then used by consumers 
or other companies, and the waste is redirected and returned to the environment or the industrial process to close the loop.

Thus, there are some countries that have an interest in developing CE implementation through laws, particularly the UK (NISP), the Netherlands (sustainable industrial parks), the US Presidential Council on sustainable Development in 1996, China (circular economy) and Japan (urban symbiosis) (Boons, Spekkink \& Mouzakitis, 2011). Moreover, all of those programs enhance the importance of industrial integration in achieving industrial symbiosis. Yet this type of integration is not new, as Porter (1998) affirmed that networking cooperation is a central to the competitive advantage for companies in the market.

\subsection{Environmental Management Maturity Stage}

In practice, the circular economy is still far from being implemented in industrial companies generally and in SMEs specifically. Despite all the methods and tools available to improve companies' environmental management, companies are at different stages of maturity. Maturity models typically describe the characteristics of a process or an activity at a number of different stages, developing from some initial stage to some more advanced stage (Fraser, Farrukh \& Gregory, 2003). The first author who came up with a classification model to describe the increasing importance of environmental concerns for business policy and strategy was Petulla (1987). Since then, many researchers have characterized corporate responses to environmental management.

The model proposed by Ormazabal, Sarriegi, Barkemeyer, Viles and McAnulla (2015) has its roots in nearly a dozen maturity models and it focuses on the path a firm can follow to move from one stage to another. This model proposes six maturity stages:

- Legal Requirements. Identify the environmental requirements that the company has to fulfill.

- Responsibility Assignment and Training. Assign a person to be in charge of environmental management and that person will assign responsibilities and manage the training that will lead to the fulfillment of almost all legal requirements.

- Systematization. Formalization of the environmental management.

- $\mathrm{ECO}^{2}$. Minimize environmental aspects through a proactive attitude, obtaining economic benefits as a result.

- Eco-Innovative Products and Services. Create new products and services that take environmental aspects into account. 
- Leading Green Company. Become a reference company in matters of environmental management through communication and marketing.

These maturity stages take place at the micro level of the CE, taking into account that there is a threelevel approach to implementing a CE in companies: micro, meso and macro (Yuan, Bi \& Moriguichi, 2006). At the micro or individual level, companies focus on their own processes and practices using cleaner production process, eco-design products and services, clean energy and raw materials and different technologies and equipment (Park et al., 2010). At the meso level, the main objective is to encourage the development of eco-industrial parks, industry associations, clusters, and networks that will benefit not only the regional economy but also the natural environment (Geng, Sarkis \& Xue, 2012). At the macro level, the circular economy is focused on the development of eco-cities, eco-municipalities or eco-provinces (Yuan et al., 2006) through the development of environmental policies and institutions influences.

\section{Methodology}

Case studies were carried out in industrial SMEs companies in the Basque Country from October 2015 to December 2015 in order to analyze the environmental management level of the companies and their degree of circular economy implementation. Case studies explore and study real-life phenomena through the detailed contextual analysis of a limited number of events or conditions and their relationships (Zainal, 2007). A total of 43 companies with fewer than 250 workers were contacted by email or telephone, but only 17 were willing to participate in the case studies, which corresponds to a response rate of $39.5 \%$. More than a half of this sample consisted of companies with 50 employees or fewer and only 11.8\% were companies that have between 100 and 250 employees (Figure 1). Companies with more than 250 employees were not taken into account to limit the research to small and medium enterprises.

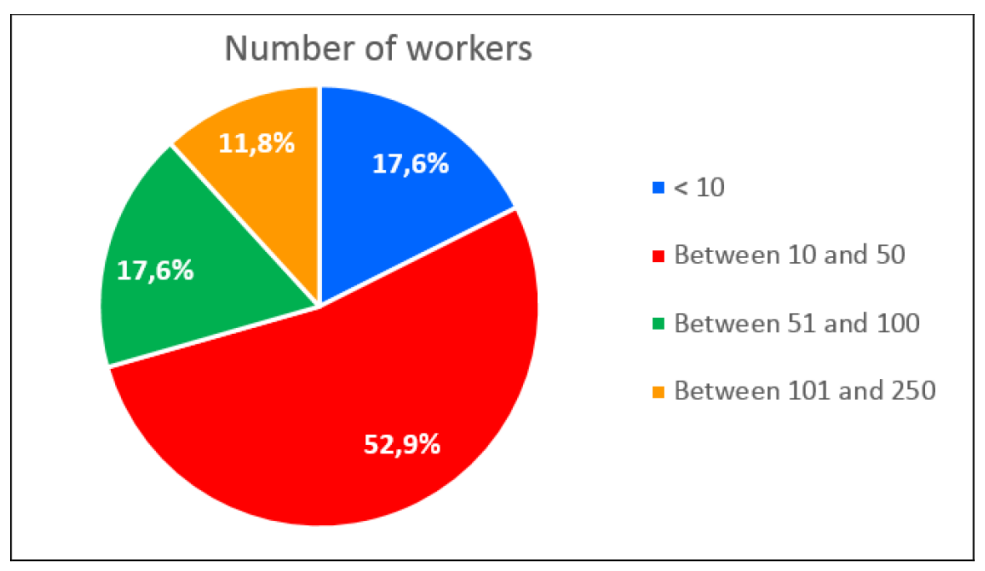

Figure 1. Companies' size 
The analysis of these companies was carried out in two different steps. First of all, an online survey was sent in order to assess the environmental management level of each company. Once the answers were evaluated, face-to-face semi-structured interviews were conducted at the companies, with meetings and personal interviews which lasted about two hours. This provided in-depth insights into the views of the corporate representatives, and allowed us to gain rich contextual information regarding the implementation of the circular economy among the companies. Questions were open-ended in order to allow a deeper exploration of issues and to allow respondents' own experiences to emerge freely (Aira, Kauhanen, Larivaara \& Rautio, 2003; Ingram, 2008).

\section{Results and Discussion}

Based on the survey design, the first aspect analyzed was the environmental management maturity level of each participant, in order to discover a possible relationship between their maturity and their capacity to implement the circular economy. Then, the survey results were focused on the circular economy cycle, the levels of integration and the barriers and opportunities that companies perceive from the circular economy.

\subsection{Environmental Management Maturity Level}

For the first stage of the maturity model, Legal Requirements, it is important to highlight that all the companies thought that they had a low environmental impact. Moreover, 70.5\% periodically review the environmental policies that could affect them, 23.5\% usually review the policies when there has been an incident, and just one of the companies confirmed that it never reviews environmental policies.

In the second stage, where the model evaluates the level of Responsibility Assignment and Training, the most evident result was that $64.7 \%$ of the companies had not assigned any person to be in charge of the environmental management of the company, which could have a direct impact on the awareness of coaching people and the actions that need to be taken to mitigate environmental damage.

In the third maturity level, Systematization, $41.2 \%$ of the companies declared that they are certified with some kind of environmental quality system such as ISO 14001 or regional certificates (Table 1). This is coherent with the number of companies that tend to include environmental aspects in their production process $(52.9 \%)$ with some frequency. 


\begin{tabular}{|l|r|}
\hline Certification & Number of Companies \\
\hline Ekoscan & 1 \\
\hline Legeskan & 1 \\
\hline Voluntary Certification: Greenhouse Gas Emissions, PEFC & 1 \\
\hline ISO 14001 & 4 \\
\hline Not Certified & 10 \\
\hline
\end{tabular}

Table 1. Environmental certifications

In the fourth stage of maturity, which is the ECO2 stage, the answers are contradictory because $64.7 \%$ of respondents rated the level of commitment of top management between 5 and 7 on a 7-point Likert scale, but only 35\% of them noted that clear environmental objectives were part of their company's strategic plan, at least in terms of projects or areas. In addition, just $17.7 \%$ thought that their company had implemented environmental guidelines that went beyond the legal ones. Additionally, more than $58.9 \%$ of participants thought that the implemented measures have a positive impact on the company's economic benefits and reputation, although the company has not implemented many improvements in the value chain of the organization. Furthermore, $70.5 \%$ of respondents rated employee participation below 3, from a total grade of 7 (Figure 2). This result may be directly related to the absence of a responsible person in charge of environmental issues to lead the consciousness among employees.

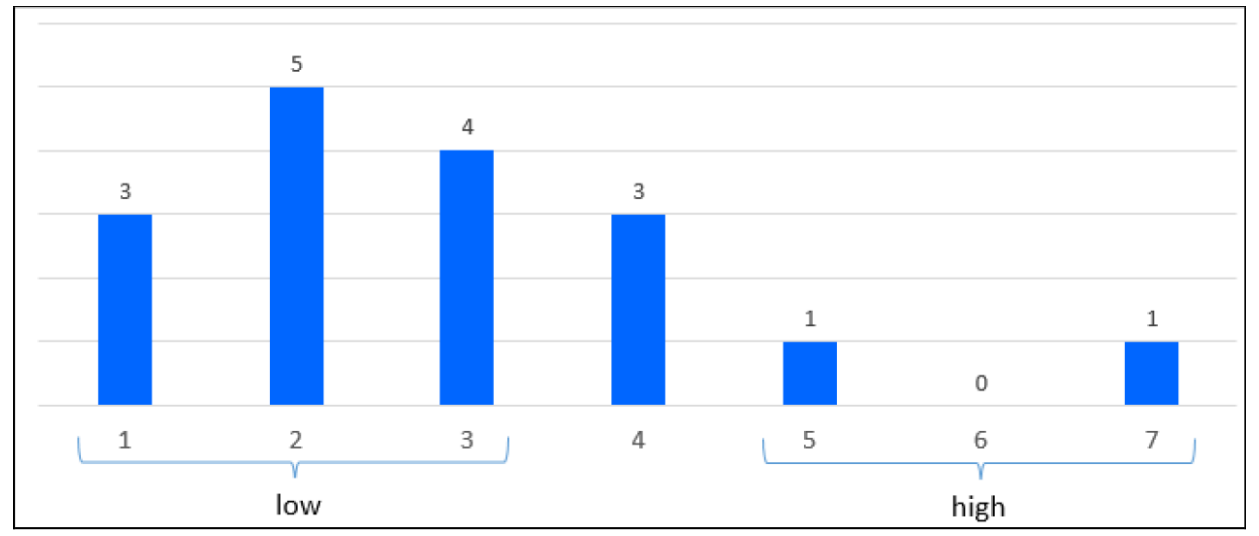

Figure 2. Employees' participation

In the fifth stage, Eco-Innovative Products and Services, $47.1 \%$ of the companies declared that they included environmental parameters in the design of the products but just $11.8 \%$ thought that environmental concerns are part of the organizational philosophy. Moreover, only $17.7 \%$ of companies have some kind of environmental certificate for their products, like ecolabels or CO2 footprint labels. It 
means that SMEs are not usually able to communicate the environmental features of their products to their consumers.

Finally, according to the previous results none of the companies considered themselves to be an environmental management leader (sixth stage). However, the authors found that $5.9 \%$ of the companies use environmental strategies to encourage their stakeholders, $11.8 \%$ use them to improve their company image and $23.5 \%$ of the firms are focused on the image of some of their products.

\subsection{CE Level of Implementation in SMEs}

In this second phase, the interviews were oriented towards studying the level of CE implementation and integration in the industry, although $64.7 \%$ of participants admitted that they had never heard of CE.

Thus, the first part was focused on the three physical flows of the product in the circular economy: Take-Make, Use, and Return-Enrich (Diez, Marangé, Mayer \& Levrat, 2016).

Regarding the Take-Make phase, the study shows that almost half of the participants do not have any environmental criteria for supplier selection (Figure 3). However, 82.3\% thought that their suppliers have a high degree of compliance with legal requirements. In this part of the interview the participants said that there was a lack of options in choosing responsible suppliers. Then, in the analysis of resources, almost $80 \%$ of the companies reported that they usually try to reduce the consumption of raw materials while designing processes, but more than a half of the participants affirmed that their materials are not easily degraded. This answer illustrates a lack of interest in the final destination of the products which cannot be up-cycled or down-cycled.

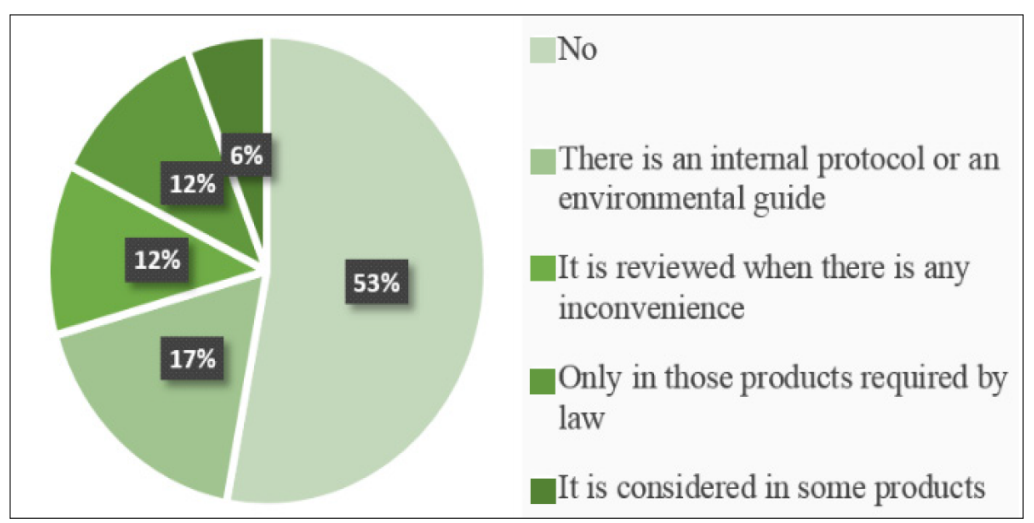

Figure 3. Green purchase criteria 
Regarding the Use phase, the developed industrial machining sector can be challenge for the Circular Economy model, because these kinds of companies work with a "business to business" model. This means that they produce materials or pieces for products that are later transformed or assembled by third producers, and therefore, they cannot control the final product. In these cases, the CE cannot be managed directly in the core business. Nevertheless, CE has opportunities to support areas like logistics, ecological modernization or the reduction of fixed costs by using CE strategies such as industrial integration (Jänicke, 2008). On the other hand, the survey suggests that the companies with a high environmental management level belong to more flexible business models, which include post-maintenance services or rental services instead of selling products. Moreover, the most sustainable companies report that they have programs for their customers in order to inform them about the correct use of their products in order to extend their life cycle.

Regarding the Return-Enrich phase, the sample may indicate that the Basque Country's industrial sector faces a significant challenge in terms of material reuse and water recovery. Just $17.6 \%$ of the companies have a water treatment plant or recirculate by-products in their processes. However, this percentage is higher $(41.1 \%)$ when companies refer to the recovery of used products that consumers do not use any more.

In the second part of the interview, the objective was to assess whether there was any integration among companies (meso and macro levels). Consequently, companies were asked about their affiliation with industry associations or clusters because their collaborative behavior help firms to improve the competitiveness and value creation (Porter, 1998). The interviews revealed that more than a third of the companies belonged to ADEGI (Association for Entrepreneurs of Gipuzkoa). However, companies agreed that associations give no support in terms of improving environmental management, except for providing legal requirements (Figure 4). Moreover, $70.6 \%$ of the companies confirmed that they have never received any advice or economic aid from the Government.

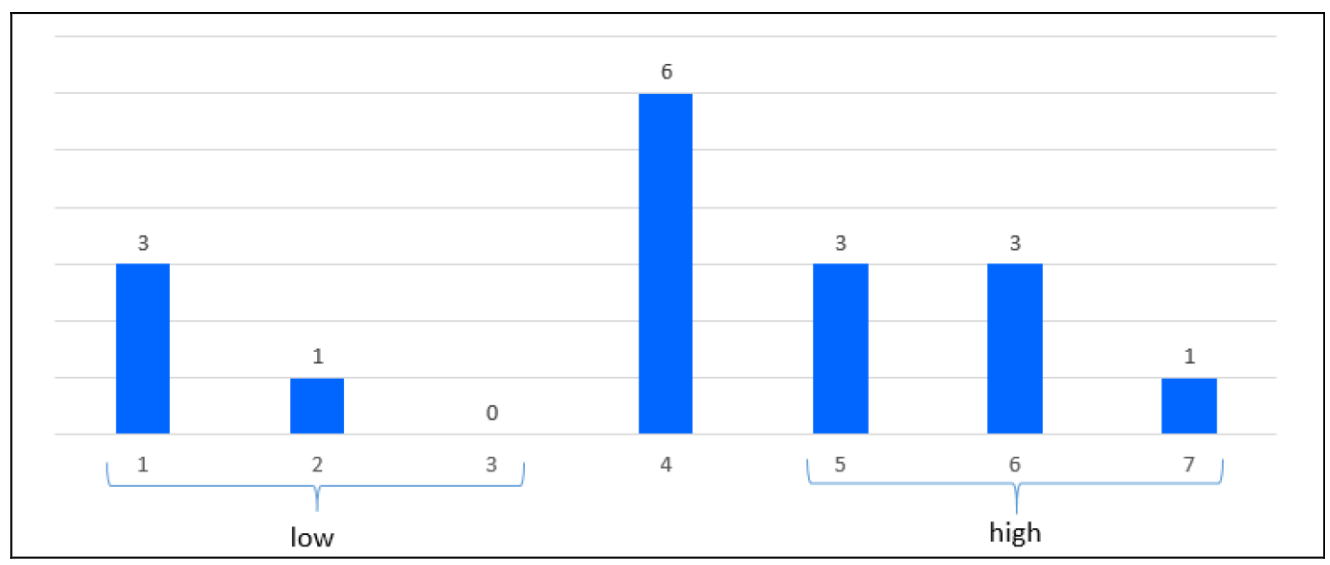

Figure 4. Business associations’ support 
In the last part of the interview, companies were asked about the benefits of implementing a CE. The enterprises with higher environmental management maturity levels agreed on three benefits: a growth in prestige, a reduction in cost, and the sustainability of the company in the future. Apart from this, however, the authors found that the majority of Basque industrial companies do not perceive any benefit from a $\mathrm{CE}$ and they rightly claim that environmental management has no impact on whether they remain in the market (Figure 5).

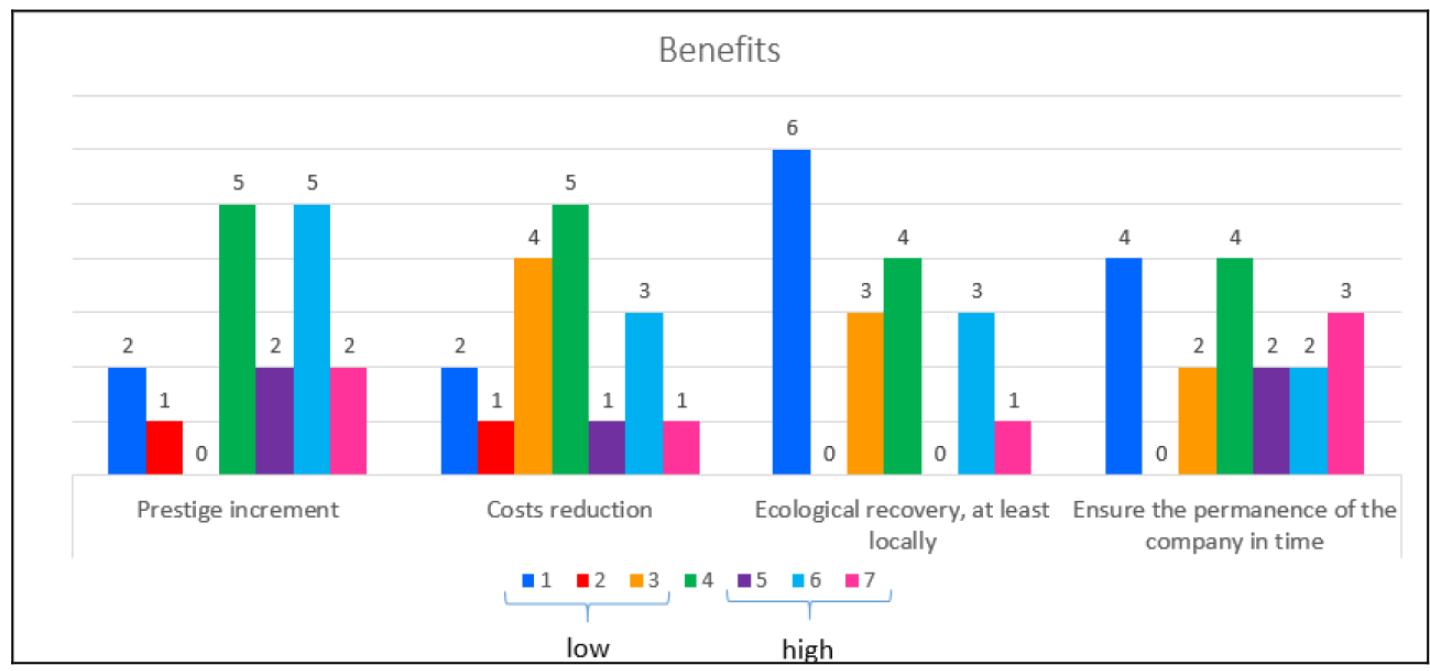

Figure 5. Benefits of implementing Circular Economy

Finally, when the research team asked about the barriers, following the Geng and Doberstein (2008) classification, participants highlighted the lack of economic incentives from the Government, the lack of technical and economic resources within the company, and the lack of customer interest in the environment. However, one of the most striking answers, even from the outstanding companies, is that they did not consider the lack of people with professional degrees in environmental fields of study as a barrier. This finding has uncovered a challenge for universities and the way they promote usefulness of their degrees, although some researchers have made an effort to share good practices in university programs (Geng, Mitchell \& Zhu, 2009).

\section{Conclusions}

In the interviews the companies tried to show environmental awareness because they recognize that it is important for the image of the company, but they do not implement active initiatives like including environmental criteria in the process or selecting a qualified person to be in charge of environmental management. This behavior is a consequence of a perception that the majority of Basque firms hold 
regarding one fundamental aspect: they do not tend to think that environmental aspects have an impact on the sustainability of their business and its success in the market. Nonetheless, they cannot know the impact of sustainable practices because they do not usually measure it in their processes. In addition, there is a clear indication that a flexible business can be a key driver in implementing a CE in the Basque Country. This conclusion must be taken into account for policies which encourage entrepreneurs and new businesses.

Moreover, the results reveled the positive relationship between the environmental management maturity level of a company with its willingness to implement the circular economy because the most mature companies have learned that environmental improvement may have positive impacts in their prestige and cost reduction.

As a final conclusion, it should be highlighted that SMEs have limited resources and do not see the Circular Economy as one of their priorities, in most cases because they do not know the benefits that this could lead to, and also because scant support is given by Governments and policy makers. In this way, the high affiliation of companies to industry associations could be used as a tool to close the loop through compatible value chains, but industry associations should improve their support in environmental issues, beyond the legal requirements. For this reason, academics should work further in developing guides for implementing a Circular Economy among SMEs, and institutions, associations and other support entities should work on giving aid in the implementation of the circular economy principles. For this purpose, it could be useful to analyze those companies that claimed to know the concept of Circular Economy, so best practices could be identified.

\section{Acknowledgements}

The authors gratefully acknowledge financial support from the Spanish National Program for Fostering Excellence in Scientific and Technical Research, and The European Regional Development Fund: DPI2015-70832-R (MINECO/FEDER).

\section{References}

Aira, M., Kauhanen, J., Larivaara, P., \& Rautio, P. (2003). Factors influencing inquiry about patients' alcohol consumption by primary health care physicians: Qualitative semi-structured interview study. Fam. Pract., 3, 270-275. http://dx.doi.org/10.1093/fampra/cmg307 
Bilitewski, B. (2007). Circular Economy in Germany. In Eleventh International Waste Management and Landfill Symposium, 1-5 October 2007, Cagliari, Italy.

Boiral, O., \& Gendron, Y. (2011). Sustainable development and certification practices: Lessons learned and prospects. Bus. Strat. Env., 5, 331-347. http://dx.doi.org/10.1002/bse.701

Boons, F., Spekkink, W., \& Mouzakitis, Y. (2011). The dynamics of industrial symbiosis: A proposal for a conceptual framework based upon a comprehensive literature review. J. Clean. Prod., 9, 905-911. http://dx.doi.org/10.1016/j.jclepro.2011.01.003

Céspedes-Lorente, J., \& De Burgos-Jiménez, J. (2004). Un análisis de las dimensiones de la gestión ambiental en los servicios hoteleros. Dirección y Organización, 5-15.

Diez, L., Marangé, P., Mayer, F., \& Levrat, E. (2016). Maintenance as a cornerstone for the application of regeneration paradigm in systems lifecycle, in: Complex Systems Design \& Management. Springer, 185-197. http://dx.doi.org/10.1007/978-3-319-26109-6_14

EEA (2011). Resource efficiency in Europe: Policies and approaches in 31 EEA member and cooperating countries.

Ellen MacArthur Foundation (2012). Towards the Circular Economy: Economic and Business Rationale for an Accelerated Transition.

Filipe, S.F., Grammatikos, T., \& Michala, D. (2016). Forecasting distress in European SME portfolios. Journal of Banking \& Finance, 112-135. http://dx.doi.org/10.1016/j.jbankfin.2015.12.007

Fraser, P., Farrukh, C., \& Gregory, M. (2003). Managing product development collaborations: A process maturity approach. Proc. Inst. Mech. Eng. Pt. B: J. Eng. Manuf., 11, 1499-1519. http://dx.doi.org/10.1243/095440503771909890

Geng, Y., \& Doberstein, B. (2008). Developing the circular economy in China: Challenges and opportunities for achieving "leapfrog development". The International Journal of Sustainable Development \& World Ecology, 3, 231-239. http://dx.doi.org/10.3843/SusDev.15.3:6

Geng, Y., Mitchell, B., \& Zhu, Q. (2009). Teaching industrial ecology at Dalian University of Technology. J. Ind. Ecol., 6, 978-989. http://dx.doi.org/10.1111/j.1530-9290.2009.00184.x

Geng, Y., Fu, J., Sarkis, J., \& Xue, B. (2012). Towards a national circular economy indicator system in China: An evaluation and critical analysis. J. Clean. Prod., 1, 216-224. http://dx.doi.org/10.1016/j.jclepro.2011.07.005 
Ingram, J. (2008). Are farmers in England equipped to meet the knowledge challenge of sustainable soil management? An analysis of farmer and advisor views. J. Environ. Manage., 1, 214-228. http://dx.doi.org/10.1016/j.jenvman.2006.12.036

Jänicke, M. (2008). Ecological modernisation: New perspectives. J. Clean. Prod., 5, 557-565. http://dx.doi.org/10.1016/j.jclepro.2007.02.011

Ormazabal, M., Sarriegi, J.M., Barkemeyer, R., Viles, E., \& McAnulla, F. (2015). Evolutionary Pathways of Environmental Management in UK Companies. Corp. Soc. Responsib. Environ. Mgmt., 3, 169-181. http://dx.doi.org/10.1002/csr.1341

Park, J., Sarkis, J., \& Wu, Z. (2010). Creating integrated business and environmental value within the context of China's circular economy and ecological modernization. J. Clean. Prod., 15, 1494-1501. http://dx.doi.org/10.1016/j.jclepro.2010.06.001

Pearce, D.W., \& Turner, R.K. (1990). Economics of natural resources and the environment. JHU Press.

Petulla, J.M. (1987). Environmental protection in the United States. San Francisco: San Francisco Study Center.

Porter, M.E. (1998). Cluster and the new economics of competition. Harv. Bus. Rev., 76(6), 77-90.

Shi, H., Peng, S., Liu, Y., \& Zhong, P. (2008). Barriers to the implementation of cleaner production in Chinese SMEs: Government, industry and expert stakeholders' perspectives. J. Clean. Prod., 7, 842-852. http://dx.doi.org/10.1016/j.jclepro.2007.05.002

Yuan, Z., Bi, J., \& Moriguichi, Y. (2006). The circular economy: A new development strategy in China. J. Ind. Ecol., 1-2, 4-8. http://dx.doi.org/10.1162/108819806775545321

Zainal, Z., 2007. Case study as a research method. Jurnal Kemanusiaan, 9, 1-6.

Journal of Industrial Engineering and Management, 2016 (www.jiem.org)

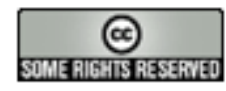

Article's contents are provided on an Attribution-Non Commercial 3.0 Creative commons license. Readers are allowed to copy, distribute and communicate article's contents, provided the author's and Journal of Industrial Engineering and Management's names are included. It must not be used for commercial purposes. To see the complete license contents, please visit http://creativecommons.org/licenses/by-nc/3.0/. 